\title{
Studi Pola Arus untuk Mengkaji Fenomena Suhu Dingin di Perairan Alor-kecil
}

\section{Rahmadiana Andini $^{1 *}$, Anindya Wirasatriya ${ }^{1}$, Muhammad Zainuri ${ }^{1}$, Kunarso $^{1}$, Aris Ismanto $^{1}$ dan $^{2}$ Jahved Ferianto Maro}

\author{
${ }^{1}$ Departemen Oseanografi, Fakultas Perikanan dan Ilmu Kelautan,Universitas Diponegoro \\ Jl. Prof. Soedarto. SH Tembalang Tlp. / Fax (024)7474698 Semarang 50275 \\ ${ }^{2}$ Departement Perikanan, Fakultas Agrikultur dan Perikanan, Universitas Tribuana Kalabahi, Alor \\ Welai Timur, Teluk Mutiara, Kabupaten Alor, Nusa Tenggara Timur
}

Email:*rahmadianaandini@gmail.com

\begin{abstract}
Abstrak
Alor-kecil merupakan sebuah desa yang berada di pesisir pantai di Kecamatan Alor Barat Laut, Kabupaten Alor, Provinsi Nusa Tenggara Timur. Perairan Alor-kecil memiliki potensi taman laut yang indah (Lau,2019). Perairan di sekitar Pulau Alor-kecil tidak hanya cantik tapi juga memiliki keunikan dari fenomena alam yaitu di perairan Alor-kecil terjadi fenomena yang disebut suhu dingin di Selat Kumbang, yang terletak antara Desa Alor Kecil dan Pulau Kepa. Salah satu parameter perairan yang penting untuk diteliti dan mempunyai pengaruh cukup tinggi terhadap parameter lainnya adalah arus laut. Penelitian ini bertujuan untuk mengetahui pola arus di Perairan Alor-kecil dan kaitannya dengan fenomena suhu dingin. Metode penelitian yang dilakukan terdiri dari pengumpulan data primer, data sekunder dan pengolahan data. Data yang diolah berupa data arus, pasang surut, batimetri, suhu, dan data angin. Hasil data lapangan dan hasil model menggunakan MIKE 21 menunjukkan bahwa Perairan Alor-kecil didominasi arus pasang surut dengan arah arus cenderung bolak-balik. Nilai formzahl sebesar 0,52 mengindikasikan adanya tipe pasang surut campuran condong ke harian ganda. Hasil pemodelan hidrodinamika menunjukkan kecepatan arus berkisar antara $0,2-0,4 \mathrm{~m} / \mathrm{s}$ pada saat pasang. Pada saat pasang menuju surut kecepatannya berkisar 0,66 - 1,33 $\mathrm{m} / \mathrm{s}$. Pada saat surut kecepatannya berkisar antara $0,08-0,2 \mathrm{~m} / \mathrm{s}$ dan pada saat pasang menuju surut kecepatannya berkisar antara 0,66 - 1,33 m/s. Pergerakan arus cenderung bolak-balik berdasarkan kondisi yaitu saat pasang dan saat surut. Ketika pasang arusnya bergerak ke arah selatan, dan ketika surut bergerak ke arah utara. Fenomena suhu dingin terjadi saat kondisi surut menuju pasang, sehingga dapat diperkirakan bahwa sumber air dingin tersebut berada pada sebelah selatan pulau, karena pola arus saat surut menuju pasang adalah ke utara. Fenomena suhu dingin di Perairan Alor-kecil diduga merupakan fenomena upwelling.
\end{abstract}

Kata kunci : Pola Arus, Fenomena Suhu Dingin, Perairan Alor-kecil, MIKE 21

\begin{abstract}
Alor-kecil is a village located on the coast in Northwest Alor District, Alor Regency, East Nusa Tenggara Province. Alor-kecil waters have the potential for a beautiful marine park Based on information from the Alor Tourism Office (2019) the waters around Alor-kecil Island are not only beautiful but also have a unique natural phenomenon, in the Alor-small waters a phenomenon called cold temperatures occurs in the Kumbang Strait, which is located between Alor-kecil Village and the Kepa Island. One of the water parameters that is important to study and has a high enough influence on other parameters is ocean currents The research method consists of primary data collection, secondary data collection and data processing. The data processed are currents, tides, bathymetry, temperature, and wind data. The results of the field data and the model results show that the Alor-kecil waters are dominated by tidal currents with the direction of the currents tending to be alternating. The formzahl value of 0.52 indicates a mixed tidal type that tends to double daily. The results of the hydrodynamic modeling show that the current velocity ranges from 0.2 to $0.4 \mathrm{~m} / \mathrm{s}$ at high tide. At the time of high tide towards low tide the speed ranges from $0.66-1.33 \mathrm{~m} / \mathrm{s}$. At low tide the speed ranges from $0.08-0.2 \mathrm{~m} / \mathrm{s}$ and at low tide the speed ranges from $0.66-1.33 \mathrm{~m} / \mathrm{s}$. Current movement tends to go back and forth based on conditions, namely at high tide and low tide. At high tide the current moves southward, and at low tide it moves north. The phenomenon of cold temperatures occurs when conditions recede towards high tide, so it can be estimated that the cold water source is in the south of the island, because the current pattern at low tide towards high tide is to the north. The phenomenon of cold temperatures in Alor-Kecil waters is thought to be an upwelling phenomenon.
\end{abstract}

Keywords : Current Pattern, Cold Temperature Phenomenon, Alor-kecil Waters, MIKE 21 


\section{PENDAHULUAN}

Alor-kecil merupakan sebuah desa yang berada di pesisir pantai di Kecamatan Alor Barat Laut, Kabupaten Alor, Provinsi Nusa Tenggara Timur, Indonesia. Potensi yang terdapat di Alor-kecil sangat beraneka ragam dan dapat dikembangkan sebagai daya tarik wisata. Perairan Alor-kecil memiliki potensi taman laut yang indah (Lau,2019). Berdasarkan informasi dari Dinas Pariwisata Alor (2019) perairan di sekitar Pulau Alor-kecil tidak hanya cantik tapi juga memiliki keunikan dari fenomena alam yaitu di perairan Alor-kecil terjadi fenomena yang disebut suhu dingin di Selat Kumbang, yang terletak antara Desa Alor Kecil dan Pulau Kepa. Air bersuhu dingin bergerak melalui perairan tersebut selama 2-3 hari berturut-turut selama dengan durasi kurang lebih 1 jam. Fenomena ini ditandai dengan datangnya gerombolan ikan ke pinggir pantai dan pergerakan lumba-lumba dan burung pemakan ikan secara besarbesaran. Ikan-ikan terdampar yang jumlahnya terbilang banyak akan ditangkap masyarakat menggunakan alat-alat sederhana, seperti serok bahkan gayung. Berdasarkan hasil wawancara yang kami lakukan pada 8 Agustus 2020 pada beberapa penduduk lokal Perairan Alor-kecil, fenomena suhu dingin tidak memiliki siklus yang tetap. Salah seorang narasumber yang bernama Arsad (60 tahun) berprofesi sebagai nelayan mengatakan bahwa saat fenomena itu terjadi air menjadi sedingin es, ditandai dengan arus yang kencang, dan terjadi 3x dalam setahun yaitu pada bulan Januari, Maret, dan Oktober. Sedangkan berdasarkan narasumber lain yaitu Bapak Latif (67 tahun) berprofesi sebagai nelayan, fenomena ini terjadi 3-4 kali dalam setahun yaitu bulan Agustus, September, Oktober, November.

Salah satu parameter perairan yang penting untuk diteliti dan mempunyai pengaruh cukup tinggi terhadap parameter lainnya adalah arus laut (Rochaddi et al 2017). Fenomena suhu dingin yang terjadi di Perairan Alor-kecil kemungkinan terkait dengan karakteristik arus laut di wilayah tersebut. Arus laut dapat diartikan sebagai sirkulasi massa air dari satu tempat ke tempat yang lain (Ismunarti dan Rochaddi,2013). Beberapa hal yang mempengaruhi pergerakan arus antara lain arah angin, perbedaan densitas air, perbedaan tekanan air, arus permukaan, dan topografi dasar laut (Kim et al., 2017). Secara umum, karakteristik arus laut di perairan Indonesia dipengaruhi oleh angin dan pasang surut (Sugianto dan Agus, 2012). Di perairan semi tertutup dan sempit seperti teluk dan selat, pasang surut merupakan gaya penggerak utama sirkulasi massa air (Dahuri et al., 2013). Penelitian ini bertujuan untuk menganalisa pola arus di Perairan Alor-kecil pada musim Timur yang diwakilkan pada bulan Agustus untuk mendukung kajian fenomena suhu dingin. Belum tersedianya data mengenai kondisi arus di Perairan Alor-kecil ini, menjadikan kajian pada lokasi penelitian dirasa perlu untuk dilakukan

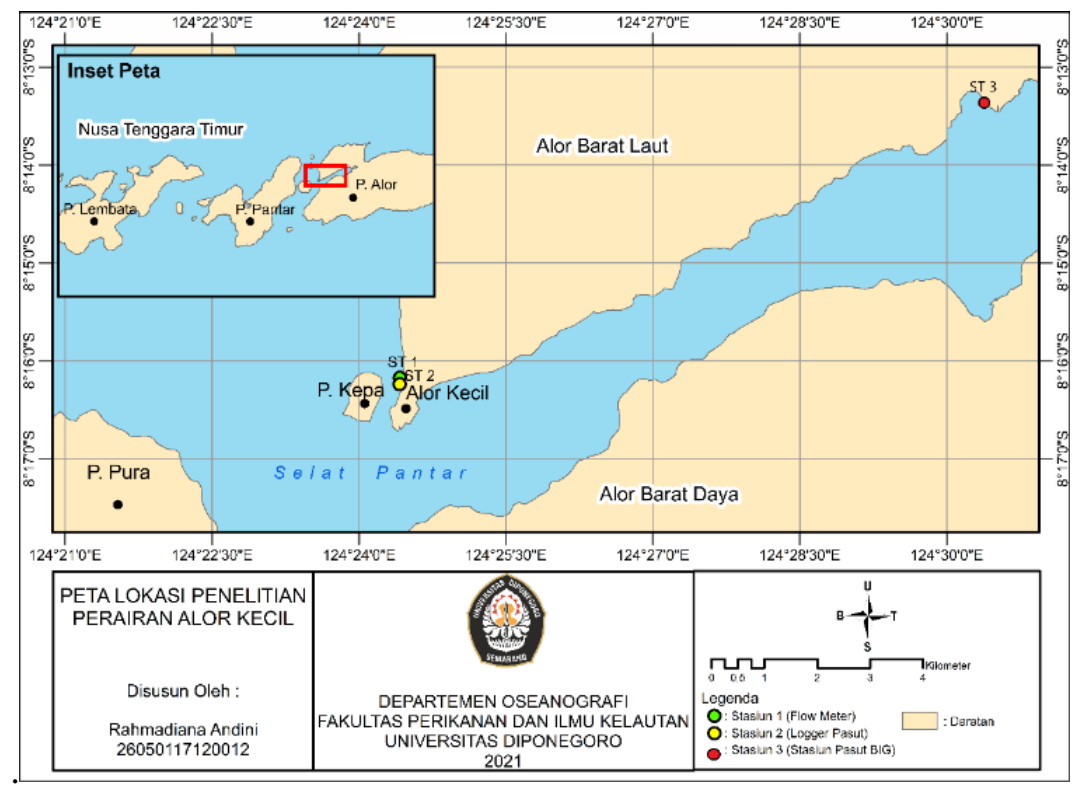

Gambar 1. Lokasi Penelitian 


\section{MATERI DAN METODE}

Penelitian ini dilakukan di Perairan Alor-kecil, NTT (Gambar 1). Materi yang digunakan dalam penelitian ini meliputi data lapangan (data primer) dan data pendukung dari instansi terkait (data sekunder). Data primer meliputi pengukuran arus, pasut, dan batimetri yang dilakukan selama 3 hari dari tanggal 8 10 Agustus 2020. Data primer tersebut digunakan untuk masukan simulasi dan sebagai data verifikasi untuk hasil modelling agar dapat diketahui pola arus yang terjadi di daerah penelitian. Data real time pasang surut bulan Agustus 2020 dari BIG juga digunakan untuk mendapatkan elevasi pasang surut. Untuk mendapatkan hasil yang maksimal maka dalam penelitian ini juga memerlukan data sekunder untuk mengetahui pemahaman tentang kondisi daerah penelitian secara regional. Data sekunder yang digunakan dalam penelitian ini adalah data angin bulan Agustus 2020 ERA-5.

Penelitian ini menggunakan metode kuantitatif. Menurut Sugiyono (2009) metode kuantitatif disebut metode ilmiah (scientific) karena memenuhi kaidah kaidah ilmiah yaitu konkrit atau empiris, obyektif, terukur, rasional dan sistematis. Metode ini menggunakan angka-angka dan analisis umumnya menggunakan statistik. Penggunaan metode kuantitatif dalam proses pengolahan data bertujuan untuk mengetahui hubungan antar variabel yang diteliti untuk mendapatkan kesimpulan dari objek yang diteliti. Pelaksanaan penelitian ini terbagi dalam tiga tahap, yakni tahap awal berupa tahap persiapan dan pengambilan data, tahap pengolahan dan analisa data, serta tahap akhir yang meliputi verifikasi data dan pengambilan kesimpulan.

Pengukuran arus laut dilakukan dengan menggunakan Current meter FLOWATCH FL-03 yang mengukur di posisi tertentu dan kedalaman tertentu yaitu pada kedalaman $5 \mathrm{~m}$ yang dilakukan tiap 1 jam selama 3 x 24 jam (8-10 Agustus 2020) dengan lokasi pengukuran terletak di 8 16' 10.98'S dan 124 24' 25.64"E. Hasil dari pengukuran tersebut didapatkan besar dan arah arus total yang diuraikan komponennya menjadi komponen $\mathrm{U}$ (sumbu $\mathrm{x}$ ) dan $\mathrm{V}$ (sumbu y) untuk kemudian di plotting kedalam beberapa grafik yang disebut dengan scatterplot dan grafik hasil analisis data arus lapangan dalam menggambarkan keadaan pola arus. Data pasang surut yang digunakan dalam penelitian ini adalah data perekaman pasang surut menggunakan Logger Pasut yang terpasang di titik $8^{\circ} 16^{\prime} 10.98^{\prime \prime} \mathrm{S}$ dan $124^{\circ} 24^{\prime} 25.64$ 'E dan nilai elevasi air laut diperoleh dengan acuan BIG pada stasiun pengamatan di Kalabahi Kepulauan Alor, NTT. Perekaman pasang surut ini didapatkan data untuk setiap interval 1 jam. Pengambilan data batimetri survei lapangan dilakukan dengan menggunakan Singlebeam Echosounder dan juga peta batimetri BATNAS. Kedua data tersebut akan diolah menggunakan perangkat lunak ArcGIS dan disimpan dalam bentuk ekstensi .xyz. Data angin yang dikumpukan dalam penelitian ini adalah data reanalysis dari ERA-5. Data model angin ini telah tervalidasi oleh data lapangan untuk mendapatkan data beresolusi tinggi $\left(0,25^{\circ} \mathrm{x}\right.$ $\left.0,25^{\circ}\right)$.

Pemodelan matematik yang digunakan adalah model 2 dimensi horizontal dengan penerapan model MIKE 21 Flow Model FM, Hydrodinamic Module. Persamaan matematik berdasarkan integrasi persamaan kontinuitas dan persamaan momentum yang dirata ratakan terhadap kedalaman. Pemodelan dilakukan dalam 4 kondisi, yaitu pada saat kondisi pasang tertinggi, surut terendah, pasang menuju surut dan surut menuju pasang. Verifikasi hasil model dilakukan dengan membandingan nilai model dengan nilai pengukuran yang bertujuan mengetahui besar kesalahan model. Pada penelitian ini verifikasi model menggunakan Root Mean Square Error (RMSE) observations standard deviation ratio (RSR) dengan persamaan berikut :

$$
\operatorname{RSR}=\left[\frac{\sqrt{\sum_{i=1}^{n}\left(y i^{\text {obs }}-y i^{\text {sim }}\right)^{2}}}{\sqrt{\sum_{i=1}^{n}\left(y i^{\text {obs }}-y i^{\text {mean }}\right)^{2}}}\right]
$$

(Moriasi et al., 2007) 
dengan yi obs adalah data hasil pengukuran, yi sim adalah data hasil simulasi dan yi mean adalah nilai rata rata hasil pengukuran. Perhitungan RSR memiliki klasifikasi seperti Sangat Baik jika bernilai 0 - 0,5; Baik jika bernilai 0,5 - 0,6; Cukup jika bernilai 0,6 - 0,7 dan Tidak baik jika bernilai $>0,7$

\section{HASIL DAN PEMBAHASAN}

Berdasarkan hasil pengukuran arus lapangan di Perairan Alor-kecil, NTT didapatkan hasil kecepatan arus pada kedalaman permukaan berkisar antara $0,028-0,58 \mathrm{~m} / \mathrm{s}$ dengan kecepatan rata-rata $0,235 \mathrm{~m} / \mathrm{s}$. Nilai arus pengukuran lapangan digunakan untuk melihat arah dan kecepatan dominan dengan membuat current rose (Gambar 2a), dimana current rose menunjukan bahwa pergerakan arus permukaan laut dominan bergerak ke timur laut dan barat daya. Sedangkan Scatter plot digunakan untuk mempresentasikan sebaran kecepatan dan arah arus laut melalui kecepatan arus pada arah timur - barat (komponen U) dan kecepatan arus pada arah utara-selatan (komponen V) (Gambar 2b).

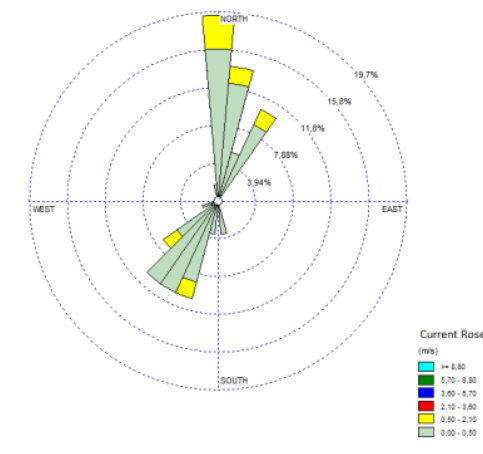

(a)

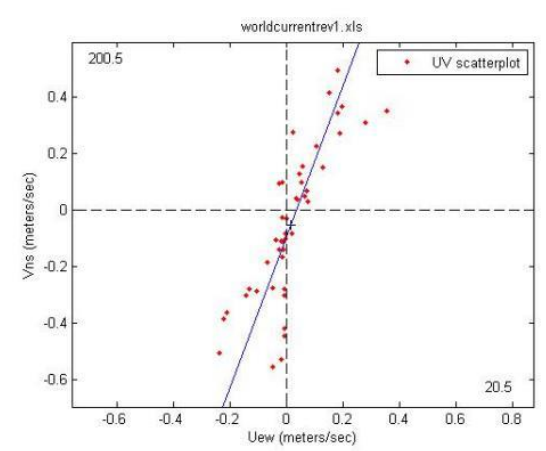

(b)

Gambar 2. Current rose (a) dan Scatter plot (b)

Karakteristik arus di Perairan Alor-kecil (Gambar 3) bertujuan untuk mengetahui jenis arus pada suatu kondisi perairan. Grafik karakteristik arus terdiri dari arus pengukuran (grafik merah), arus astronomi (grafik biru) dan arus residu (grafik hijau). Didapatkan hasil fluktuasi kecepatan arus data lapangan memiliki pola yang hampir sama dengan data astronomic (arus pasang surut). Sehingga dapat dikatakan bahwa arus yang mendominansi pada Perairan Alor-kecil adalah arus pasang surut.

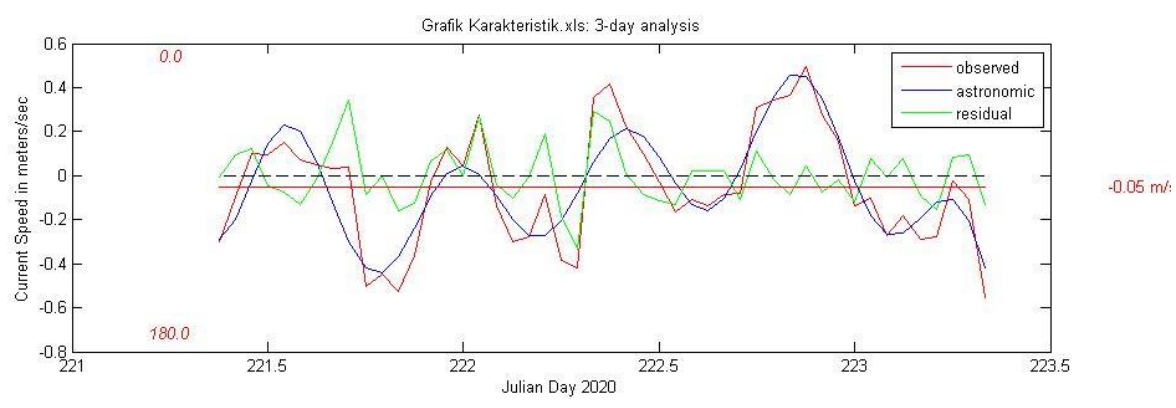

Gambar 3. Grafik Karakteristik Arus Laut Perairan Alor-kecil, NTT

Analisis harmonik komponen pasang surut dilakukkan dengan metode admilarty untuk mendapatkan nilai amplitudo dan fase dari komponen pasang surut. Pengolahan data pasang surut dilakukan dengan menggunakan metode admilarty dan didapatkan nilai Formzahl sebesar 0,52 (Gambar 4). Nilai tersebut menunjukan bahwa tipe pasang surut di Perairan Tapaktuan adalah campuran condong ke harian ganda. 
Nilai elevasi muka air tertinggi, Highest High Water Level (HHWL) adalah $321 \mathrm{~cm}$, muka air terendah, Lowest Low Water Level (LLWL) -16,3cm dan tinggi muka air rata rata, Mean Sea Level (MSL) sebesar $152 \mathrm{~cm}$.

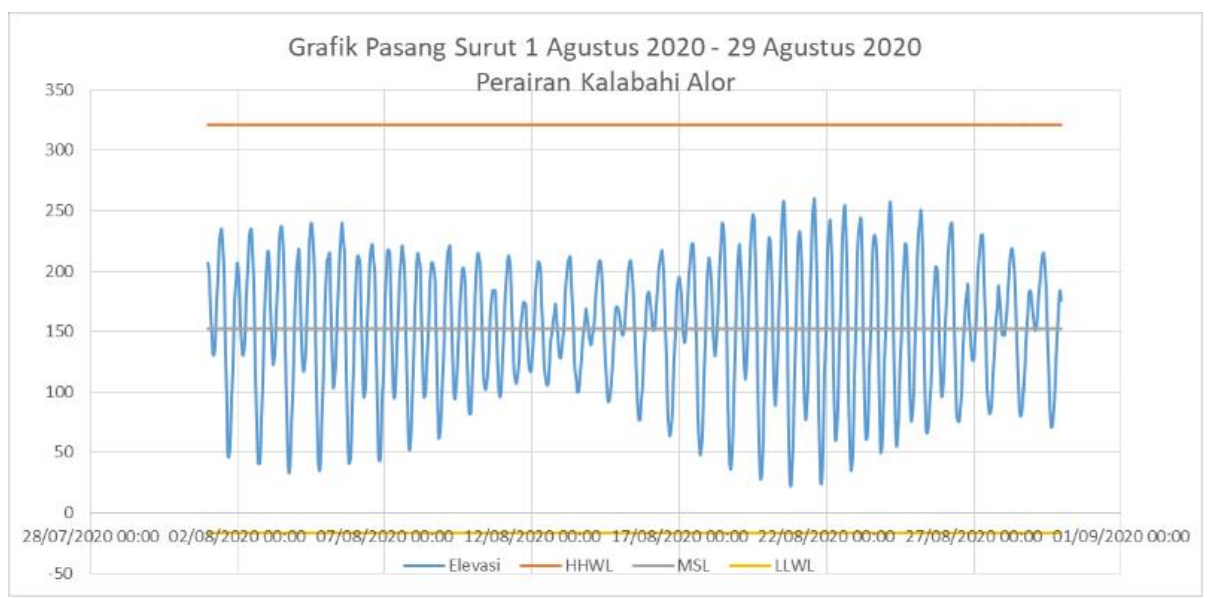

Gambar 4. Grafik Pasang Surut Perairan Alor-kecil, NTT

Berdasarkan hasil pengolahan data menunjukkan bahwa arus di Perairan Alor-kecil didominasi oleh arus pasang surut, terlihat dari grafik pemisah arus yang didapat dari World Current dimana arus pengukuran memiliki pola yang mendekati grafik astronomic (arus pasang surut). Pada penyajian data dengan scatter plot komponen $\mathrm{u}$ dan $\mathrm{v}$ arus juga berbentuk elips sebagai ciri dari arus pasang surut dimana gerak pola arus secara eliptikal maka arus di perairan tersebut didominasi oleh arus pasut karena mengikuti siklus pasang surut sesuai dengan letak lintang, arus pasut akan bergerak secara kontinyu dengan arah yang berubah secara bertolak belakang atau pergerakan arus terjadi cenderung bersifat bolak-balik pada interval waktu tertentu. Menurut Brown (1989) arah arus pasang surut cenderung bergerak bolak balik, dengan arah arus saat pasang berkebalikan pada saat surut. Adanya pergerakan arus tersebut diakibatkan oleh adanya perbedaan elevasi muka air laut karena gaya tarik bulan dan matahari yang mengakibatkan terjadinya perbedaan tekanan hidrostatik antara satu tempat dengan tempat yang lainnya, dimana elevasi yang tinggi mempunyai tekanan hidrostatik yang lebih besar dibandingankan dengan elevasi yang lebih rendah. Perbedaan tekanan yang bekerja pada permukaan horizontal ini akan mengakibatkan gaya yang disebut dengan gaya gradient tekanan, dimana gaya ini akan mengakibatkan massa air mengalami perpindahan yaitu bergerak dari tekanan yang tinggi ke tekanan yang rendah.

Fenomena suhu dingin di Perairan Alor-kecil diduga merupakan fenomena upwelling. Menurut Yuhendrasmiko et al., 2016, upwelling merupakan proses terangkatnya massa air dari dasar perairan yang memiliki suhu dingin dan kaya akan zat hara ke permukaan. Mekanisme upwelling tersebut diduga karena pergerakan massa air (arus) dari arah selatan membawa massa air dingin dari dasar perairan dan terbawa oleh arus pasang surut menuju selat Kumbang atau Perairan Alor-kecil. Menurut Raharjo dan Saputra (2017), kondisi morfologi dasar laut dari suatu perairan khususnya di selat dapat mempengaruhi kecepatan arus laut. Fenomena suhu dingin ini terjadi kemungkinan karena perbedaan kedalaman antara laut yang berada pada sebelah selatan pulau tersebut yaitu Samudera Hindia dengan Laut Sawu. Massa air yang begitu besar dan densitas berbeda dengan permukaan kemudian terbawa dengan arus pasang surut memasuki Perairan Alor-kecil membawa air dingin. Menurut Aziz (2006) arus yang gaya pembangkitnya pasang surut sangat dominan dalam proses sirkulasi air laut di perairan pantai. Arus pasang surut pada saat pasang mentransporkan air dari laut menuju perairan pantai, dan pada saat surut mentransporkan air dari perairan pantai ke laut lepas. 


\section{KESIMPULAN}

Berdasarkan hasil penelitian Kajian Pola Arus di Perairan Alor-kecil dan Kaitannya dengan Fenomena Suhu Dingin didapatkan hasil kecepatan arus pada kedalaman permukaan berkisar antara 0,028 $-0,58 \mathrm{~m} / \mathrm{s}$ dengan kecepatan rata-rata $0,235 \mathrm{~m} / \mathrm{s}$. Pergerakan arus cenderung bolak-balik berdasarkan kondisi yaitu saat pasang dan saat surut. Fenomena suhu dingin di Perairan Alor-kecil diduga fenomena upwelling. Mekanisme upwelling tersebut diduga karena pergerakan massa air (arus) dari arah selatan membawa massa air dingin dari dasar perairan dan terbawa oleh arus pasang surut menuju selat Kumbang atau Perairan Alor-kecil.

\section{DAFTAR PUSTAKA}

Hadi, S. dan I. M. Radjawane. 2009. Arus Laut. Institut Teknologi Bandung (ITB), Bandung.

Ismanto, Aris , D. H. Ismunarti, D. N. Sugianto, S. Maisyarah, P.Subardjo, A. A. Suryoputro, H. Siagian. 2019. The Potential of Ocean Current as Electrical Power Sources Alternatives in Karimunjawa Islands Indonesia. Advances in Science, Technology and Engineering Systems Journal, 4(6):126133.

Ismunarti,D.H. dan B. Rochaddi. 2013. Kajian Pola Arus Di Perairan Nusa Tenggara Barat Dan Simulasinya Menggunakan Pendekatan Model Matematik. Buletin Oseanografi Marina, 4 : 1-11.

Lau, E. R. A. 2019. Potensi Desa Alor Kecil Sebagai Desa Wisata di Kabupaten Alor Nusa Tenggara Timur. J. Tourism, 2(1):32-38.

Rizki, N., L. Maslukah, D. N. Sugianto, A. Wirasatriya, M. Zainuri, A. Ismanto, A. R. Purnomo, and A. D. Ningrum. 2021. Distribution of DO (Dissolved Oxygen) and BOD (Biological Oxygen Demand) in the Waters of Karimunjawa National Park Using Two-Dimensional Model Approach. IOP Conf. Series, Earth and Environmental Science 750, IOP Publishing.

Rochaddi, Baskoro., A. Ismanto, C. A. Suryono, dan S. Widada. 2021. Variasi Temporal Karakteristik Arus di Perairan Tanjung Jati, Jepara. J. Kelautan Tropis, 24(3):255-264

Surbakti, H. 2012. Karakteristik Pasang Surut dan Pola Arus di Muara Sungai Musi Sumatera Selatan. Jurnal Penelitian Sains. 15(1).

Sugianto, D.N., dan Agus, A.D.S., 2012. Pola Sirkulasi Arus Laut di Perairan Pantai Provinsi Sumatera Barat. Indonesian Journal of Marine Sciences, 12(2):79-92..

Triatmodjo, B. 1999. Teknik Pantai. Beta Offset, Yogyakarta.

Yuhendrasmiko, Randy., Kunarso, dan A. Wirasatriya. 2016. Identifikasi Variabilitas Upwelling Berdasarkan Indikator Suhu dan Klorofil-A di Selat Lombok. J. Oseanografi, Vol 5(4) : 530-537 